\title{
Simultaneous estimation of canagliflozin and metformin hydrochloride in tablet dosage form by UV spectrophotometry
}

\author{
D. Sharmila ${ }^{1, *}$, J. Chandini ${ }^{2}$, K. Vasantha Lakshmi ${ }^{3}$, Ch. Hari Balaji ${ }^{4}$, A. Lakshmana Rao ${ }^{5}$ \\ ${ }^{1}$ Associate Professor, ${ }^{2-4}$ UG Student, ${ }^{5}$ Principal, Dept. of Pharmaceutical Analysis, V. V. Institute of Pharmaceutical Sciences, \\ Gudlavalleru, Andhra Pradesh, India \\ *Corresponding Author: \\ Email: sharmiladonepudi@gmail.com
}

\begin{abstract}
The combination of Canagliflozin and Metformin was available as fixed dose tablets for the treatment of type 2 diabetes. The present method aims to develop a simple, precise and accurate spectrophotometric method for simultaneous determination of Canagliflozin and Metformin in commercial formulation. The method utilizes Vierordt's equation based on the measurement at two wavelengths $290 \mathrm{~nm}$ ( $\lambda \max$ of Canagliflozin) and $236 \mathrm{~nm}$ ( $\lambda \max$ of Metformin). The method exhibited linear range of 2.5 to $15 \mu \mathrm{g} / \mathrm{ml}$ and 5 to $17.5 \mu \mathrm{g} / \mathrm{ml}$ for Canagliflozin and Metformin, respectively, with a correlation coefficient of 0.999 . The LOD and LOQ for Canagliflozin were found to be 0.43 and 1.31 respectively. For Metformin the LOD and LOQ were found to be 0.49 and 1.49 respectively. The recovery of Canagliflozin and Metformin were found to be 99.43 and 98.82 respectively. The results were validated statistically as per ICH guidelines and were found to be satisfactory. To conclude, the developed UV spectrophotometric method is more economical for analysis of Canagliflozin and Metformin in both bulk and pharmaceutical dosage form for routine analysis.
\end{abstract}

Keywords: Canagliflozin, Metformin, Vierordt's equation, UV-Spectrophotometry, ICH guidelines.

\section{Introduction}

The combination of Canagliflozin and Metformin is indicated as an adjunct to diet and exercise to improve glycemic control in adults with type-2 diabetes. The Canagliflozin and Metformin formulation is available in four dose strengths $(50 / 500 \mathrm{mg}$, $50 / 1000 \mathrm{mg}, 150 / 500 \mathrm{mg}, 150 / 1000 \mathrm{mg}$ ) and should be taken twice daily with food. ${ }^{1}$ Canagliflozin (Fig. 1a) is chemically (1S)-1, 5-anhydro-1-[3-[[5-(4fluorophenyl)-2-thienyl]methyl]-4-methylphenyl]-Dglucitol and belongs to the class of SGLT2 inhibitors. It is used in the treatment of type-2 diabetes. ${ }^{2}$ Canagliflozin inhibits the reabsorption of glucose from kidneys and lowers the renal glucose threshold by inhibiting sodium-glucose transport protein (SGLT2) ${ }^{3-4}$ By blocking SGLT2, Canagliflozin decreases reabsorption of filtered glucose and reduces the renal threshold for glucose $\left(\mathrm{RT}_{\mathrm{G}}\right)$, thereby elevating the urinary glucose excretion (UGE) and reducing raised plasma glucose in patients with type-2 diabetes. ${ }^{5}$ Canagliflozin can be used as monotherapy or multi therapy in the treatment of type- 2 diabetes..$^{6-9}$

Metformin (Fig. 1b) a biguanide antihyperglycemic agent used for treating type-2 diabetes. It acts by decreasing hepatic glucose production and glucose absorption, and it enhances insulin mediated glucose uptake. Metformin is recommended as first line therapy for patients with type- 2 diabetes. Patients, from whom Metformin monotherapy is not sufficient to achieve glycemic goals, it is referred to use in combination with other class of antidiabetic drugs. ${ }^{10}$

The literature survey revealed that few analytical methods were reported for estimation of the drugs individually and in combination using, UV, ${ }^{11-13}$
HPLC ${ }^{14-16}$ HPTLC $^{17}$ and LC-MS. ${ }^{18}$ In the present study an attempt was made for simultaneous estimation of Canagliflozin and Metformin in pharmaceutical dosage form by UV spectrophomerty. The method can be applied for routine quality control analysis.

\section{Materials and Method}

Reagents and Chemicals: The pure sample of Canagliflozin and Metformin was procured from Selleckchem LLC supplied by Pro lab marketing, India. The commercial formulations (Invokamet tablets containing $150 \mathrm{mg}$ of Canagliflozin and $500 \mathrm{mg}$ of Metformin) were procured from the local market. Methanol (AR grade) was purchased Merck Chemical Division, Mumbai, India and was used as diluent. Fresh purified distilled water was used throughout the experiment.

Instrumentation: Shimadzu UV1800 Double Beam UV-Visible Spectrophotometer, using software UV Probe (version 2.42) was used for spectral studies. Shimadzu BL220H Digital Weighing Balance having sensitivity of $0.001 \mathrm{~g}$ was used for weighing the materials.

\section{Method Development}

Standard solution preparation: About $100 \mathrm{mg}$ of Canagliflozin and 100mg of Metformin was accurately weighed and transferred into a $100 \mathrm{~mL}$ clean dry volumetric flask containing $70 \mathrm{~mL}$ of methanol. The solution was sonicated for $5 \mathrm{~min}$ and the drug was dissolved completely. The volume was made up to the mark with a further quantity of the methanol to get a stock concentration of $1 \mathrm{mg} / \mathrm{mL}$ Canagliflozin and Metformin. From the above prepared stock solution 
$1 \mathrm{~mL}$ was transferred into a $10 \mathrm{~mL}$ volumetric flask and the volume was made up to the mark with the methanol to obtain $100 \mu \mathrm{g} / \mathrm{mL}$. The resulting solution was further diluted to obtain the concentration of $10 \mu \mathrm{g} / \mathrm{mL}$ for both drugs separately and scanned from 400-200nm. The spectra of Canagliflozin with $290 \mathrm{~nm}$ as $\lambda \max$ and of Metformin with $236 \mathrm{~nm}$ as $\lambda \max$ were obtained.

Preparation of sample solution: Twenty tablets were weighed and finely powdered. An accurately weighed portion of powder sample equivalent to $150 \mathrm{mg}$ of Canagliflozin and 500mg Metformin of was transferred into a $100 \mathrm{~mL}$ clean dry volumetric flask containing $70 \mathrm{~mL}$ of methanol. The solution was sonicated for $5 \mathrm{~min}$ and the drug was dissolved completely and to mark with methanol. The solution was subjected to filtration using Whatman filter paper No 41 . The $0.5 \mathrm{~mL}$ stock was further diluted $10 \mathrm{~mL}$ with methanol, from which $1 \mathrm{~mL}$ is transferred to $10 \mathrm{~mL}$ volumetric flask and further diluted with methanol. The final drug mixture dilution was subjected for analysis.

Preparation of calibration Standards: Working standard solutions were prepared for the Canagliflozin and Metformin from the standard solution of $100 \mu \mathrm{g} / \mathrm{mL}$. Different aliquots were taken from standard stock solution and diluted with methanol separately to prepare 2.5 to $15 \mu \mathrm{g} / \mathrm{mL}$, and 5 to $17.5 \mu \mathrm{g} / \mathrm{mL}$ for Canagliflozin and Metformin respectively. Then the construction of calibration curve was plotted by taking the above prepared solutions by taking the concentration and absorbance values.

Simultaneous equation method (Vierodt's method): The approach was possible when two analytes have dissimilar $\lambda \max$, each of which exhibits absorbance at the $\lambda$ max of other. Two equations are constructed based on the fact that the absorbance at a particular wavelength is sum of individual absorbance of two components. Absorptivity from all the concentration was calculated for both the drugs in methanol solution and used for the development of simultaneous equation.

$$
\begin{gathered}
C_{X}=A_{2} a_{y_{1}}-A_{1} a_{y_{2}} / a_{x_{2}} a_{y_{1}}-a_{x_{1}} a_{y_{2}} \ldots \ldots \ldots \ldots . . . \ldots \\
C_{y}=A_{1} a_{x_{2}}-A_{2} a_{x_{1}} / a_{x_{2}} a_{y_{1}}-a_{x_{1}} a_{y_{2}} \ldots \ldots \ldots \ldots \text { (2) }
\end{gathered}
$$

The concentration of Canagliflozin (Cx) and Metformin $\left(\mathrm{C}_{\mathrm{y}}\right.$ ) can be obtained by solving above equation (1) and (2)

Where,

i) $504.74\left(\mathrm{a}_{\mathrm{X}_{1}}\right)$ and $232.29\left(\mathrm{a}_{\mathrm{X}_{2}}\right)$ are absorptivity of Canagliflozin at $\lambda_{1}(290 \mathrm{~nm})$ and $\lambda_{2}(236 \mathrm{~nm})$ respectively.

ii) $80.81\left(\mathrm{a}_{\mathrm{y}_{1}}\right)$ and $388.82\left(\mathrm{a}_{2}\right)$ are absorptivity of Metformin at $\lambda_{1}(290 \mathrm{~nm})$ and $\lambda_{2}(236 \mathrm{~nm})$ respectively.

$A_{1}$ and $A_{2}$ are absorbance of mixture at $\lambda_{1}(290 \mathrm{~nm})$ and $\lambda_{2}(236 \mathrm{~nm})$ respectively.

\section{Method validation}

The method was validated as per ICH guidelines to study various parameters like linearity, accuracy, precision etc.

Linearity: The linearity of the method was developed by plotting absorbance vs concentration $(\mu \mathrm{g} / \mathrm{mL})$. The linearity for Canagliflozin was established over a concentration range of $2.5-15 \mu \mathrm{g} / \mathrm{mL}$ and for Metformin $5-17.5 \mu \mathrm{g} / \mathrm{mL}$ respectively. The correlation coefficient was calculated by analysing regression equation.

Accuracy: The accuracy of the method was determined by standard addition method. A known amount of standard drug was added to the fixed amount of preanalysed drug sample solution. Percent recovery was calculated by comparing the absorbance before and after the addition of the standard drug. The standard addition method was performed at three concentration levels in triplicate at $80 \%, 100 \%$ and $120 \%$.

Precision: Precision is the degree of repeatability of an analytical method under normal operational conditions. The precision of the method was confirmed by intraday and inter-day analysis. The concentration used for the precision studies is $10 \mu \mathrm{g} / \mathrm{mL}$ of Canagliflozin and $10 \mu \mathrm{g} / \mathrm{mL}$ Metformin was assumed as $100 \%$. The precision of the developed method was expressed in terms of \% relative standard deviation (RSD).

Limit of Detection and Limit of Quantification (LOD and LOQ): The LOD and LOQ were calculated based on the standard deviation of response and slope. The standard deviation of the response can be determined based on the standard deviation of $y$ intercepts of regression lines.

\section{Results and Discussion}

From the spectrum of analytes, the $\lambda \max$ of Canagliflozin and Metformin was found to be $290 \mathrm{~nm}$ and $236 \mathrm{~nm}$ respectively. The linear regression data showed a good linear relationship over a concentration range, 2.5 to $15 \mu \mathrm{g} / \mathrm{mL}$ and 5 to $17.5 \mu \mathrm{g} / \mathrm{mL}$ for Canagliflozin and Metformin respectively, with a correlation 0.999 for both drugs. The linearity data was submitted in Table 1 and Fig. 4 and 5. By performing assay for marketed dosage from, the percentage drug estimated was found to be $99.33 \pm 0.832 \%$ for Canagliflozin and $100.80 \pm 0.521 \%$ for Metformin. The results obtained were within the limit of $\pm 2 \%$, the accuracy data was given Table 2 . The percentage recovery of pure drug for Canagliflozin ranged from 97.84 to 101.00 and for Metformin 98.40 to 99.45 respectively. The results were presented in Table 3 . The method developed was proved to be precise as \% RSD values for both intra-day and inter-day were within the limit of $\pm 2 \%$, the data was presented in Table 4 and 5 . The limit of detection for Canagliflozin and Metformin was found to be $0.43 \mu \mathrm{g} / \mathrm{mL}$ and $0.49 \mu \mathrm{g} / \mathrm{mL}$ respectively. Limit of quantification was found to be $1.31 \mu \mathrm{g} / \mathrm{mL}$ and $1.49 \mu \mathrm{g} / \mathrm{mL}$ for Canagliflozin and Metformin respectively. 
Table 1: Linearity data of Canagliflozin and Metformin

\begin{tabular}{|c|c|c|c|c|}
\hline \multirow{2}{*}{ S. No. } & \multicolumn{2}{|c|}{ Canagliflozin at 290nm } & \multicolumn{2}{c|}{ Metformin at 236nm } \\
\cline { 2 - 5 } & $\begin{array}{c}\text { Concentration } \\
(\boldsymbol{\mu g} / \mathbf{m L})\end{array}$ & Absorbance & $\begin{array}{c}\text { Concentration } \\
(\boldsymbol{\mu g} / \mathbf{m L})\end{array}$ & Absorbance \\
\hline 1 & 2.5 & 0.120 & 5 & 0.199 \\
\hline 2 & 5 & 0.234 & 7.5 & 0.298 \\
\hline 3 & 7.5 & 0.384 & 10 & 0.384 \\
\hline 4 & 10 & 0.511 & 12.5 & 0.475 \\
\hline 5 & 12.5 & 0.656 & 15 & 0.576 \\
\hline 6 & 15 & 0.799 & 17.5 & 0.668 \\
\hline Regression Equation & \multicolumn{2}{|c|}{0.999} & \multicolumn{2}{c|}{0.999} \\
\hline $\begin{array}{c}\text { Correlation } \\
\text { Coefficient }\left(\mathrm{r}^{2}\right)\end{array}$ & \multicolumn{2}{|c|}{0.0281} & \multicolumn{2}{c}{} \\
\hline
\end{tabular}

Table 2: Assay results of Canagliflozin and Metformin in formulations

\begin{tabular}{|c|c|c|c|c|}
\hline \multicolumn{2}{|c|}{ Formulation } & Label claim & Amount found & \% Assay \\
\cline { 2 - 5 } Inokamet $®$ & Canagliflozin & $150 \mathrm{mg}$ & $148.99 \mathrm{mg}$ & $99.33 \% \pm 0.832$ \\
\cline { 2 - 5 } & Metformin & $500 \mathrm{mg}$ & $504 \mathrm{mg}$ & $100.80 \% \pm 0.521$ \\
\hline
\end{tabular}

Table 3: Recovery studies for Canagliflozin

\begin{tabular}{|c|c|c|c|c|}
\hline \multirow{2}{*}{ Level } & \multicolumn{2}{|c|}{ Canagliflozin } & \multicolumn{2}{c|}{ Metformin } \\
\cline { 2 - 5 } & $\begin{array}{c}\text { \% Recovery } \\
(\mathbf{n}=\mathbf{3})\end{array}$ & \%RSD & $\begin{array}{c}\text { \% Recovery } \\
(\mathbf{n}=\mathbf{3})\end{array}$ & \%RSD \\
\hline $80 \%$ & $99.46 \pm 0.420$ & 0.422 & $98.40 \pm 0.093$ & 0.094 \\
\hline $100 \%$ & $\begin{array}{c}101.00 \pm \\
0.525\end{array}$ & 0.520 & $99.45 \pm 0.493$ & 0.496 \\
\hline $120 \%$ & $97.84 \pm 0.238$ & 0.243 & $98.60 \pm 0.420$ & 0.426 \\
\hline
\end{tabular}

Table 4: Intra-day precision results of Canagliflozin and Metformin

\begin{tabular}{|c|c|c|c|}
\hline S. No. & Time (Hours) & Canagliflozin & Metformin \\
\hline 1 & 0 & 0.513 & 0.362 \\
\hline 2 & 3 & 0.515 & 0.361 \\
\hline 3 & 6 & 0.511 & 0.355 \\
\hline 4 & 9 & 0.509 & 0.357 \\
\hline 5 & 12 & 0.510 & 0.359 \\
\hline 6 & 15 & 0.508 & 0.363 \\
\hline \multicolumn{2}{|r|}{ Mean } & 0.511 & 0.360 \\
\hline \multicolumn{2}{|r|}{ SD } & 0.003 & 0.003 \\
\hline \multicolumn{2}{|r|}{ \%RSD } & 0.51 & 0.86 \\
\hline
\end{tabular}

Table 5: Inter-day precision results of Canagliflozin and Metformin

\begin{tabular}{|c|c|c|c|}
\hline S. No. & Time (Days) & Canagliflozin & Metformin \\
\hline 1 & 1 & 0.515 & 0.362 \\
\hline 2 & 2 & 0.509 & 0.359 \\
\hline 3 & 3 & 0.510 & 0.360 \\
\hline 4 & 4 & 0.514 & 0.365 \\
\hline 5 & 5 & 0.507 & 0.365 \\
\hline 6 & 6 & 0.501 & 0.359 \\
\hline \multicolumn{2}{|c|}{ Mean } & 0.509 & 0.361 \\
\hline \multicolumn{2}{|c|}{ \%D } & 0.005 & 0.003 \\
\hline
\end{tabular}



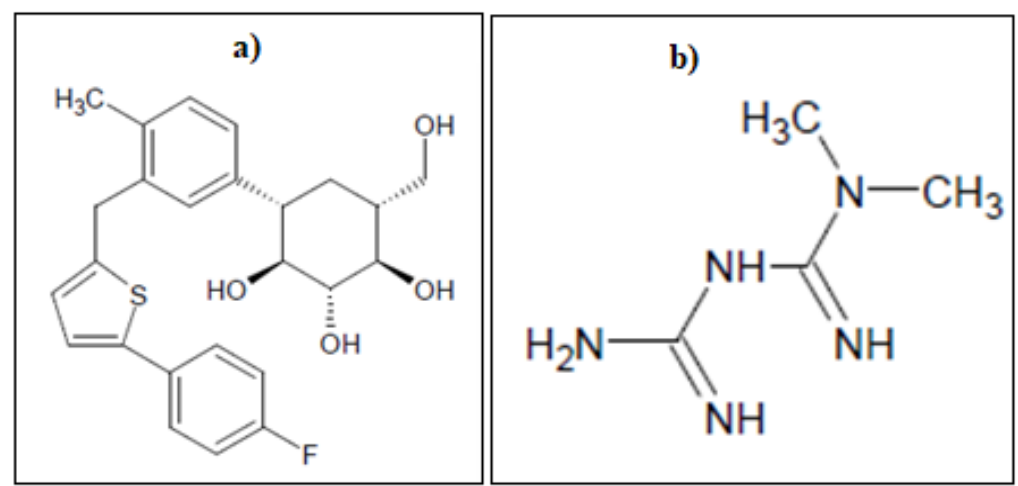

Fig. 1: Structure of Canagliflozin (a) and Metformin (b)

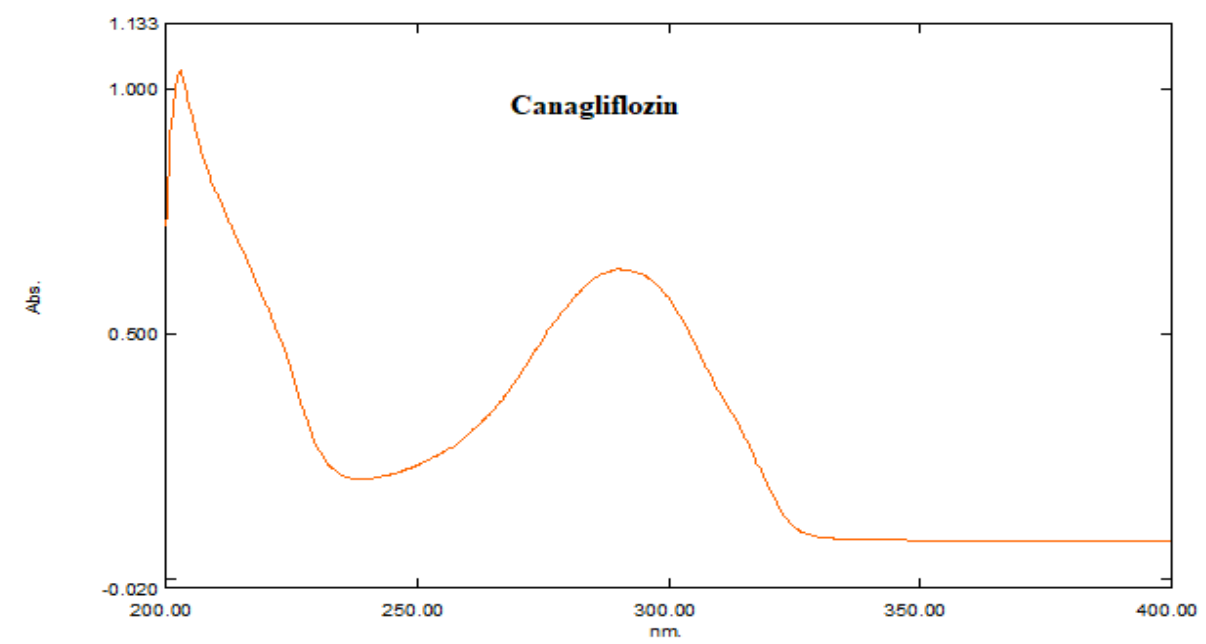

Fig. 2: Spectrum of Canagliflozin

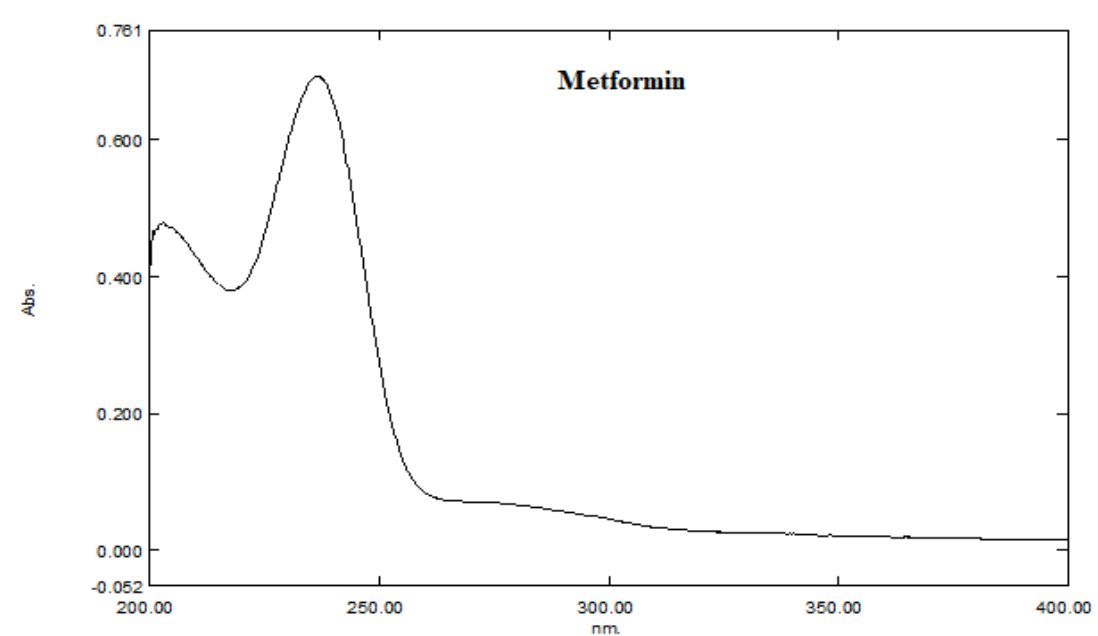

Fig. 3: Spectrum of Metformin 


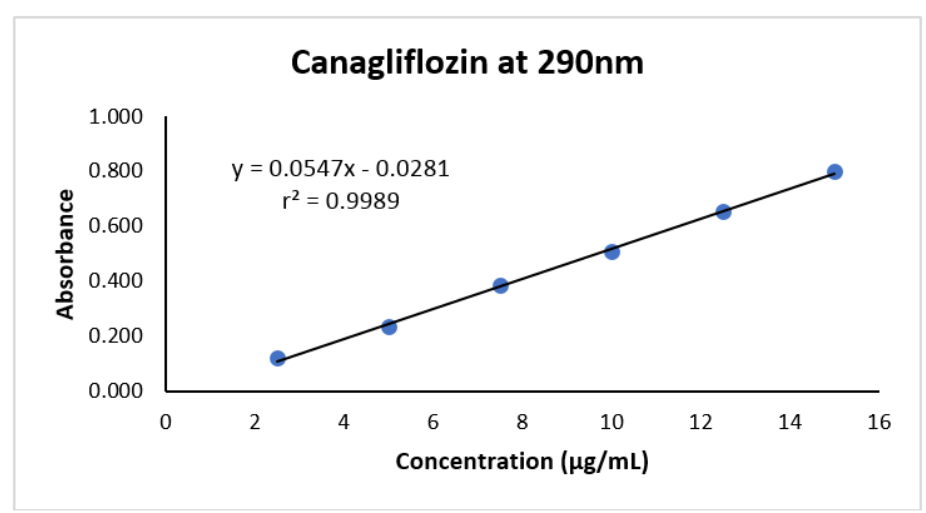

Fig. 4: Calibration curve of Canagliflozin at 290nm

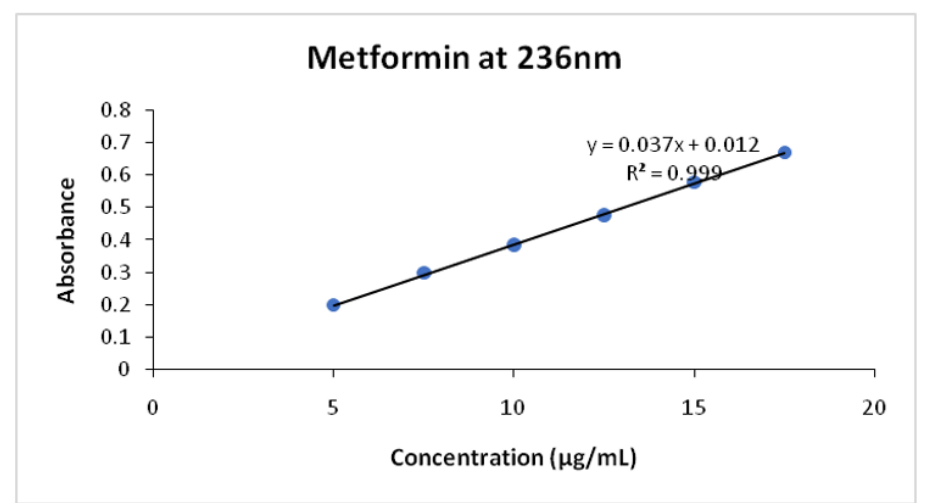

Fig. 5: Calibration curve of Metformin at 236nm

\section{Conclusion}

The proposed spectrophomertic method is simple, accurate, precise and economical for the simultaneous estimation of Canagliflozin and Metformin in bulk and dosage form. The results obtained indicate method compliances with ICH limits. Percentage assay is very near to label claim which shows accuracy of the method. On the basis of validation and assay data it was concluded that the developed method can be utilized for routine analysis of selected combination.

\section{Acknowledgement}

The authors are thankful for the management of $\mathrm{V}$. V. Institute of Pharmaceutical Sciences, Gudlavalleru, for providing all necessary facilities to carry out this work.

\section{References}

1. Qiu R, Balis D, Capuano G, et.al. "Canagliflozin: Efficacy and safety in combination with Metformin alone or with other antihyperglycemic agents in type 2 diabetes". Diabetes Ther 2016;7(4):659-78.

2. Drug monograph Canagliflozin fromhttp://www.drugbank.ca/drugs/DB08907

3. Ghosh RK, Ghosh SM, Chawla S et.al. "SGLT2 inhibitors: a new emerging therapeutic class in the treatment of type 2 diabetes mellitus". J Clin Pharmacol 2012;52(4):457-63.

4. Invokana (Canagliflozin) package insert. Titusville, NJ: Janssen Pharmaceuticals, Inc; March 2013.
5. Prasanna Kumar KM, Ghosh S, Canovatchel W, et.al. "Review of clinical efficacy and safety of Canagliflozin $300 \mathrm{mg}$ in the management of patients with type 2 diabetes mellitus". Ind J Endocrinol Metab 2017;21(1):196-209.

6. Poudel RR; "Renal glucose handling in diabetes and sodium glucose cotransporter 2 inhibition". Ind $J$ Endocrinol Metab 2013;17:588-93.

7. Devineni D, Curtin CR, Polidori D, et.al "Pharmacokinetics and pharmacodynamics of Canagliflozin, a sodium glucose co-transporter 2 inhibitor, in subjects with type 2 diabetes mellitus". $J$ Clin Pharmacol 2013;53(6):601-10.

8. Invokana. Janssen Pharmaceuticals, Inc. www.invokana.com. (Accessed September 17, 2017).

9. Dietrich E, Powell J, Taylor JR. "Canagliflozin: a novel treatment option for type 2 diabetes”. Drug Des Devel Ther 2013;7:1399-408.

10. Davidson JA, Sloan L. "Fixed-Dose Combination of Canagliflozin and Metformin for the Treatment of Type 2 Diabetes: An Overview". Adv Ther 2017;34(1):41-59.

11. Kaur I, Wakode S and Singh HP. "Development and Validation of UV Spectroscopic Method for Determination of Canagliflozin in Bulk and Pharmaceutical Dosage Form". Pharm Methods 2015;6(2):82-6.

12. Krupa Karuna Vani B. "UV and Derivative Spectrophotometry Method for the estimation of Canagliflozin in pharmaceutical formulations". Int J A PS BMS 2017;6(1):022-9.

13. Mubeen G and Noor K. "Spectrophotometric Method for Analysis of Metformin Hydrochloride". Ind J Pharm Sci 2009;71(1):100-2. 
14. Gaware D, Patil RN, Harole M. "A validated stability indicating RP-HPLC method for simultaneous determination of Metformin and Canagliflozin in pharmaceutical formulation". World J Pharm Pharm Sci 2015;4(12):631-40.

15. Panigrahy UP, Reddy ASK. "A novel validated RPHPLC-DAD method for the simultaneous estimation of Metformin hydrochloride and Canagliflozin in bulk and pharmaceutical tablet dosage form with forced degradation studies". Orient J Chem 2015;31(3):1489507.

16. D'Souza, Krishna S, Sushmitha M, et.al. "Stability indicating assay method development and validation to simultaneously estimate Metformin hydrochloride and Canagliflozin by RP-HPLC". Curr Trends Biotechnol Pharm 2016;10(4):334-42.

17. Bhole RP, Gandhi JS, Wankhede SB. "Development and validation of HPTLC method for simultaneous estimation of Canagliflozin and Metformin hydrochloride in bulk and tablet dosage form". S Afr Pharm J 2017;84(6):6571.

18. Kobuchi S, Yano K, Ito Y, et.al., "A validated LCMS/MS method for the determination of Canagliflozin, a sodium-glucose co-transporter 2 (SGLT-2) inhibitor, in a lower volume of rat plasma: application to pharmacokinetic studies in rats". Biomed Chromatogr 2016;30(10):1549-55.

19. ICH Harmonised tripartite guideline, Validation of analytical procedures: text and methodology, Q2 (R1). 2005:1-13. 